\title{
Tribological impact of the finishing technology onto meso- and microforming processes
}

\author{
Stephan F. Jahnn ${ }^{1, a}$, Benedikt Müller ${ }^{1}$, Felix S. Hilfinger ${ }^{1}$, and Andreas Schubert ${ }^{1,2}$ \\ ${ }^{1}$ Professorship Micromanufacturing Technology, Technische Universität Chemnitz, 09107 Chemnitz, \\ Germany \\ ${ }^{2}$ Fraunhofer Institute for Machine Tools and Forming Technology, Reichenhainer Str. 88, \\ 09126 Chemnitz, Germany
}

\begin{abstract}
Tribological conditions between workpiece and tool have a major impact onto forming processes. Besides lubrication, temperature, and material, they are mainly influenced by the tool surface characteristics, especially by its topography, which is a result of finishing technology. Thereby formed lubricant pockets are of prime importance for the tribosystem due to its ability to separate the tribopartners by storing lubricant. The influence of four different tool finishing processes and their according surface topographies onto frictional behaviour have been investigated and quantified by the barrel compression test, in dry and lubricated tribosystems. The tool steel surfaces were stochastically microstructured by grinding and spark erosion as well as deterministic structured with micro calottes, applied by jet electrochemical machining and compared to a polished reference tool. The allocation of open and closed lubricant pockets over tool surfaces before and after the forming process was analysed by a self-made MATLAB tool.
\end{abstract}

\section{Introduction}

Microproducts such as downsized mechanical or electrical systems or microsystems sensors and actuators are of growing demand in many branches due to their great benefits which are compact size, low weight and power consumption as well as low manufacturing costs. Since micro-manufacturing technologies gains more and more importance in producing microparts, a well-founded knowledge of their frictional behaviour is required for reproducible production processes of high quality. Especially in meso- and microforming processes tribological conditions are of major concern in terms of final shape, wear and surface quality [1]. So called size effects need to be considered as well while scaling down dimensions into sub-millimetre range [2]. Tiny tool structures which are required to form tiny microstructures could not always be finished by polishing. Hence, the surface of these tool structures is defined by the manufacturing technology, e.g. milling, spark erosion (EDM), electrochemical machining (ECM), or laser ablation. Forming processes are highly influenced by the friction between tool and workpiece resulting of the mechanical contact caused by process related high loads. Friction has a

\footnotetext{
${ }^{\text {a }}$ Corresponding author: stephan.jahn@mb.tu-chemnitz.de
}

This is an Open Access article distributed under the terms of the Creative Commons Attribution License 4.0, which permits unrestricted use, distribution, and reproduction in any medium, provided the original work is properly cited. 


\section{MATEC Web of Conferences}

massive impact in terms of forming resistance and therefore onto the total forming force needed. It effects the material flow and thus the final shape of the workpiece. Surface topography of the forming tool is a major characteristic of the tribosystem. Roughness peaks interfere with the workpiece surface during relative motion which increases the friction force and promotes abrasive wear. In general, by lowering the roughness of the tool surface friction force is decreasing. But very smooth surfaces, e.g. produced by polishing, could act friction-increasing because of increasing adhesion forces. Liquid lubricants, applied to separate the tribopartners and lower shear forces, could be squeezed out in case of a very smooth surfaces. Microstructured surfaces could provide the ideal tool topography to reach minimal friction forces [3]. Surfaces that are characterized by a high number of small roughness valleys can store lubricant in lubricant pockets. Valleys that are unconnected to the edge of the contact area are called closed lubricant pockets and lower friction forces by developing a selective hydrostatic pressure under the applied forming load. Open lubricant pockets are linked to the edge of the contact area. They are unable to build up a hydrostatic pressure and therefore have only a little friction-lowering impact. Surface characterisation in terms of proportion of material and open lubricant pockets and closed lubricant pockets can be described by the ratio of the closed void area as a function of the material penetration and its maximum $\alpha_{\mathrm{clm}}$. By integration of the function, the normalised closed void volume $\mathrm{V}_{\mathrm{cl}}$ can be calculated, which describes the percentage of the lubricant store volume of a 3D-surface [4]. Depending on the manufacturing technologies, tool surfaces can differ in terms of surface roughness as well as shape and orientation of the created microstructure. In case of cutting processes such as milling or grinding, a characteristic kinematic roughness will describe the topography of the tool surface. In case of abrasive techniques like Jet-ECM [5], EDM or laser ablation, a stochastic or deterministic allocation of positive or negative asperities in the form of elevations or cavities will define the surface structure. A major advantage of deterministic structures is the creation of closed lubricant pockets in a defined shape and ratio over the contact area.

Friction conditions in forming processes can be determined and evaluated by friction tests like the pin extrusion test [6], the double cup extrusion test [1], the slide-compression test [7], or the barrel compression test [8]. In this paper, the barrel compression test was chosen to quantify the tribological impact of four differently finished tool surfaces. The barrel compression test provides a simple way to calculate the friction factor out of geometrical parameters, measured before and after the test (Fig. 1). The parameters measured for calculation are the initial height $\mathrm{H}_{0}$, the initial diameter $\mathrm{D}_{0}$, the height after compression $\mathrm{H}_{1}$ and the maximum sample diameter $\mathrm{D}_{\mathrm{m}}$, which depends on the friction-dependent barrelling of the cylinder while being compressed. The friction factor describes the relation between friction shear stress $\tau$ and flow stress $\mathrm{k}_{\mathrm{f}}$ :

$$
m=\sqrt{3} \cdot \frac{\tau}{k_{f}} .
$$

According to [8] the friction factor $m$ is calculated by:

$$
m=\frac{\frac{R}{H} \cdot b}{\frac{4}{\sqrt{3}}-\frac{2 b}{3 \sqrt{3}}}
$$

where $\mathrm{b}$ represents the barrel parameter and $\mathrm{R}$ the average radius after deformation. Both parameters are also easily calculated out of $\mathrm{H}_{0}, \mathrm{D}_{0}, \mathrm{H}_{1}, \mathrm{D}_{\mathrm{m}}$ and $\mathrm{R}_{\mathrm{T}}$ [8].

\section{Experimental procedure}

Four different pairs of upper and lower tool stamps were made of hardened 1.3343 tool steel (64 HRC). All stamps were polished. One polished pair of stamps was kept as reference tool set (Fig. 2a). Two pairs of stamps were stochastically microstructured by creating grinding marks through outside peripheral grinding (Fig. 2b) and by spark erosion (Fig. 2c). The fourth pair was deterministically structured by 

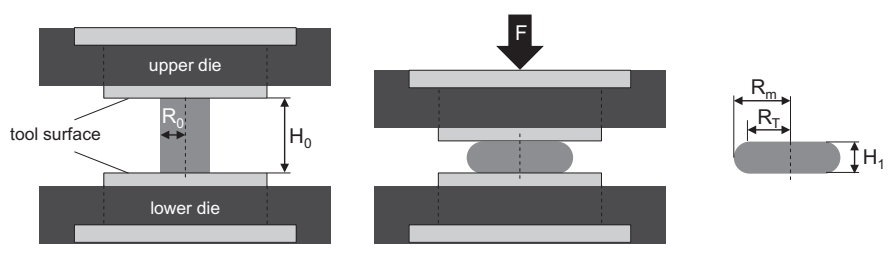

Figure 1. Principle and geometric parameters of the barrel compression test.

Table 1. Investigated parameters.

\begin{tabular}{|l|l|}
\hline Parameter & Values \\
\hline Specimen material & AlMg3/Cu-ETP \\
\hline Forming degree $\varphi=\ln \left(H_{1} / H_{0}\right)$ & $-0,17 /-0,4 /-0,51 /-0,69 /-0,88 /-1,10 /-1,30$ \\
\hline Stamp structure & polished / grinding marks / erosion craters / micro calottes \\
\hline Lubrication & no lubrication / forming oil (Plantoform MBO 2797) \\
\hline
\end{tabular}

using jet electrochemical machining (Fig. 2d). Micro calottes with diameters of $200 \mu \mathrm{m}$ and depths of $11 \mu \mathrm{m}$ were generated. The cylinder samples were machined on a precision-turning machine from one bar of AlMg3 and $\mathrm{Cu}$-ETP, respectively. Figure 2e shows the resulting sample surface, due to the kinematic roughness of the turning process. The samples were heat-treated after machining at $380^{\circ} \mathrm{C}$ in a 10 mbar nitrogen atmosphere. Each sample was measured twice in height and diameter by a micrometre before and after the compression. The cylinder size was measured with $\mathrm{D}_{0}=4,999 \pm 0,005 \mathrm{~mm}$ and $\mathrm{H}_{0}=7,498 \pm 0,008 \mathrm{~mm}$. Images from tool and sample surfaces were taken by an optical microscope Nikon MM-400 and by a 3D-Laser scanning microscope Keyence VK-9710. 3D-Laser images were used to calculate the areal roughness values over $213 \times 284 \mu \mathrm{m}^{2}$ (Fig. 2f). 3D-Laser images over $1000 \times 1000 \mu \mathrm{m}^{2}$ were taken to characterize the dies' surfaces concerning the ratios of material area as well as open and closed void areas. Therefore, a MATLAB tool was developed. Tool stamps were integrated into a servo precision forming press from Hegewald \& Peschke which is located in a clean room of class 100.000. Before each compression test, the samples were cleaned in an ethanol ultrasonic bath for $5 \mathrm{~min}$ and tool surfaces were wiped with ethanol. For lubricated experiments, one drop of forming oil was applied manually on the tool surface as well as on the top side of the cylinder after placing it into the lubricant drop. In case of dry tests, the sample was placed directly on the plane tool surface. Each parameter combination according to Table 1 was conducted twice under consideration of the machine elastic recovery to ensure the desired forming degrees. During the tests, forming temperature and stamp velocity were held constantly at $20^{\circ} \mathrm{C}$ and $3 \mathrm{~mm} / \mathrm{min}$.

\section{Results and discussion}

Figure 3 shows the area ratio diagrams for the four different tool surfaces. Blue lines represent material, green lines open void areas and red lines closed void areas with its maximum at $\alpha_{\mathrm{clm}}$. The polished and grinded surfaces show no significant difference in terms of void area ratios, penetration depth of $\alpha_{\mathrm{clm}}$ and the closed void volume $\mathrm{V}_{\mathrm{cl}}$. The eroded surface exhibits a similar spreading of area ratios but with a higher closed void area. However, Fig. $3 c$ obviously indicates that the penetration depth of $\alpha_{\mathrm{clm}}$ is very high. Therefore no closed lubrication pockets can be created by sealing the closed void area after first contact of roughness peaks of tool and workpiece surfaces. Compared to that, the surfaces with micro calottes show high values for $\alpha_{\mathrm{clm}}$, too, but at a lower penetration depth, i.e. the closed lubricant pockets are sealed and effective at a moderate contact pressure between tool and workpiece. Furthermore, $\mathrm{V}_{\mathrm{cl}}$ is more than five times higher compared to all the other tool surfaces, which means that a high amount of lubricant can be stored within the micro calottes. 

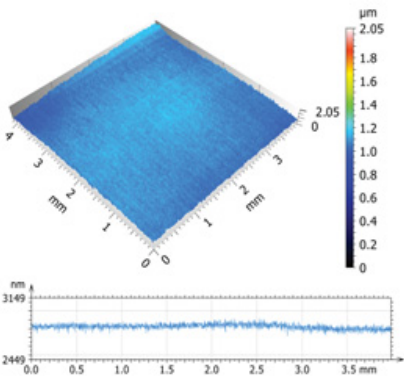

a) polished

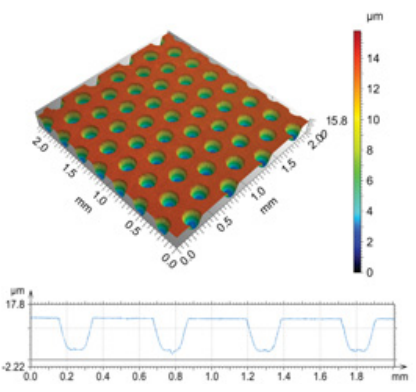

d) micro calottes

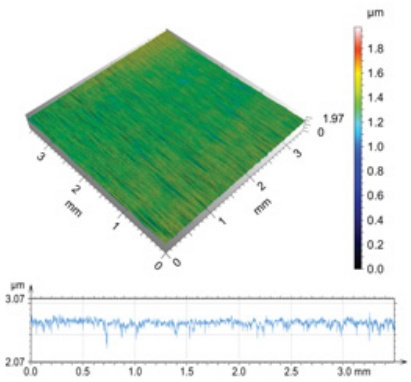

b) grinding marks

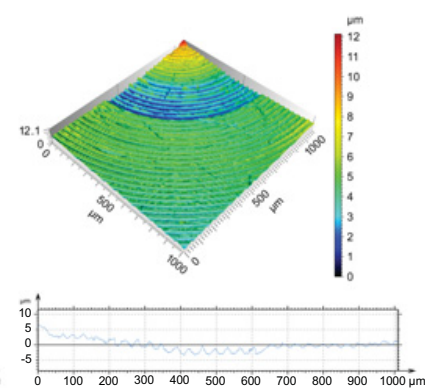

e) sample surface

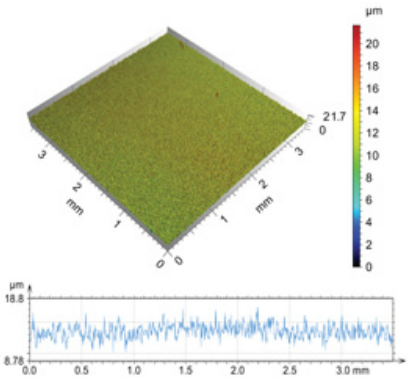

c) erosion craters

\begin{tabular}{c|c|c}
\hline surface & $\mathbf{S}_{\mathbf{a}}[\boldsymbol{\mu m}]$ & $\mathbf{S}_{\mathbf{q}}[\boldsymbol{\mu m}]$ \\
\hline polished & 0,032 & 0,041 \\
$\begin{array}{c}\text { grinding } \\
\text { marks } \\
\text { erosion } \\
\text { craters } \\
\text { micro }\end{array}$ & 0,053 & 0,071 \\
calottes & 2,936 & 1,118 \\
$\begin{array}{c}\text { AlMg3 } \\
\text { samples }\end{array}$ & 0,586 & 0,542 \\
$\begin{array}{c}\text { Cu-ETP } \\
\text { samples }\end{array}$ & 0,561 & 0,698 \\
\hline
\end{tabular}

f) surface roughness

Figure 2. 3D images, 2D profiles and surface roughness of tool and sample surfaces.
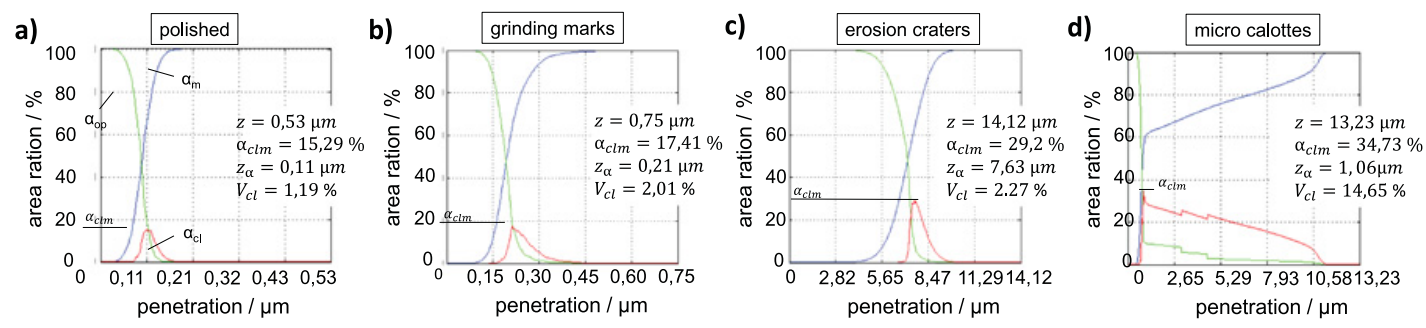

material $\alpha_{m} \quad$ open void area $\alpha_{o p} \quad$ closed void area $\alpha_{c l}$

Figure 3. Area ratio diagrams with profile height $\mathrm{z}$, closed void area $\alpha_{\mathrm{clm}}$, penetration depth of closed void area $\mathrm{z}_{\alpha}$ and closed void volume $\mathrm{V}_{\mathrm{cl}}$.

Figure 4 shows the friction factor for experiments with $\mathrm{AlMg} 3$ and $\mathrm{Cu}-\mathrm{ETP}$ samples in dependency on the forming degree. Continuous lines represent dry experiments and dotted lines lubricated tribosystems. All tool and material combinations show a related course of friction factor with increasing values to a maximum, followed by a slight decay. The rising part of the curve can be explained by the increasing friction shear stress $\tau$ due to an increasing real contact area resulting of smoothed roughness peaks on the workpiece surface. Therefore, according to Eq. (1), the friction factor is increasing with rising forming degree. In case of lubricated tribosystems, with rising forming degree, the lubricant gets more and more squeezed out of the lubrication pockets. This leads to a less hydrostatic support, which means, $\tau$ and therefore the friction factor is increasing. The drop of friction factor can be explained by its dependency on the flow stress $\mathrm{k}_{\mathrm{f}}$ and friction shear stress. While $\tau$ is levelling out to a constant value with increasing real contact area at high forming degrees, the friction factor decreases due to a rising flow stress as a result of strain hardening. Both materials show a similar spreading of friction factors for 

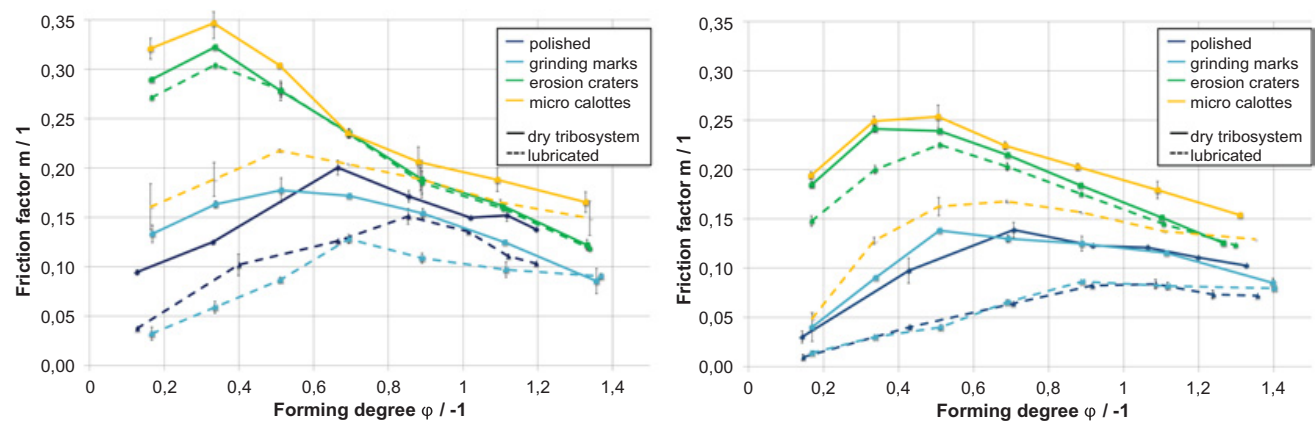

Figure 4. Friction factor over forming degree for $\mathrm{AlMg} 3$ (left) and $\mathrm{Cu}-\mathrm{ETP}$ (right).

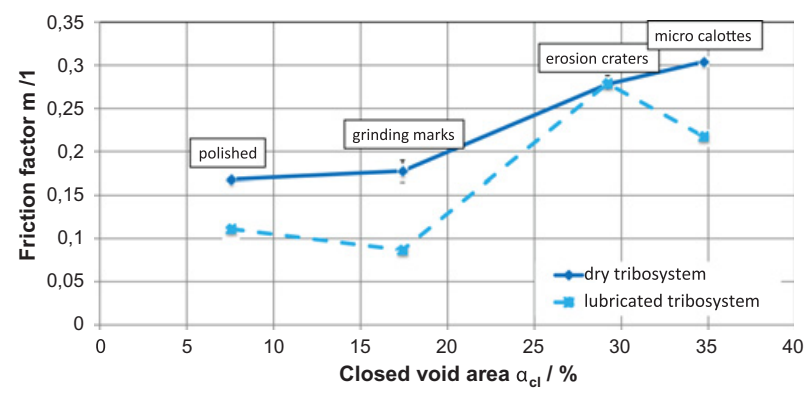

Figure 5. Friction factor over closed void area $\alpha_{\mathrm{clm}}$ for $\mathrm{AlMg} 3$ samples at $\varphi=-0,51$.

forming degrees over 0,8 with and almost comparable values. At forming degrees below 0,8 , aluminium leads to 1,5 to 2 times higher friction factors than copper. In general it can be said, that a higher tool surface roughness leads to increasing friction forces. The quite low and very similar roughness values for tools with grinding marks and the polished reference result in relatively low friction factors. Contrary to that, the high roughness values of surfaces with erosion craters and micro calottes result in up to two times higher friction factors, especially in unlubricated tests. This matches with the fact that rough tool surfaces interfere with the relative motion because the softer workpiece material is pressed into the roughness valleys [9]. Figure 4 also shows the friction-decreasing effect of lubrication in case of the polished reference tool and for tools with grinding marks and micro calottes. Tool surfaces with erosion craters form an exception: lubrication shows no significant decrease of friction. Figure 5 shows the friction factor in dependency on the closed void area for aluminium samples at a forming degree of $-0,51$ for dry and lubricated tribosystems. As already mentioned, the tool surface with erosion craters shows no friction-decreasing effect under the influence of lubrication, despite the fact that the ratio of closed void area $\alpha_{\mathrm{clm}}$ and therefore the possible area of hydrostatic pressure is even higher compared to polished tools and tools with grinding marks. The most likely reason for this phenomenon is the fact, that the maximum of closed area ratio lies in a profile depth of about 7,63 $\mu \mathrm{m}$. The sample surface must be flattened and pressed into the tool surface in a high level before the lubricant can be trapped in the resulting closed lubricant pockets. Until this point mainly less effective open lubricant pockets are responsible for taking external load by building a hydrodynamic pressure. But with rising forming degrees and increasing normal pressure the lubricant gets easily squeezed out of the open lubrication pocket, due to their connection to the boarder of the contact zone. Therefore the friction lowering effect is vanishing for tools with erosion craters when reaching higher forming degrees as can be seen in Fig. 4. 

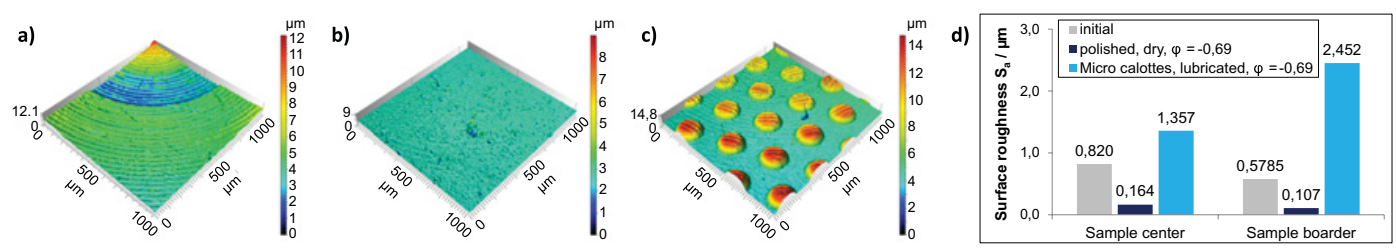

Figure 6. AlMg3 sample face side surface of initial (a), polished, dry, $\varphi=-0,69$ (b), micro calottes, lubricated, $\varphi=-0,69$ (c) and root square roughness $S_{q}$ of sample centre and boarder (d).
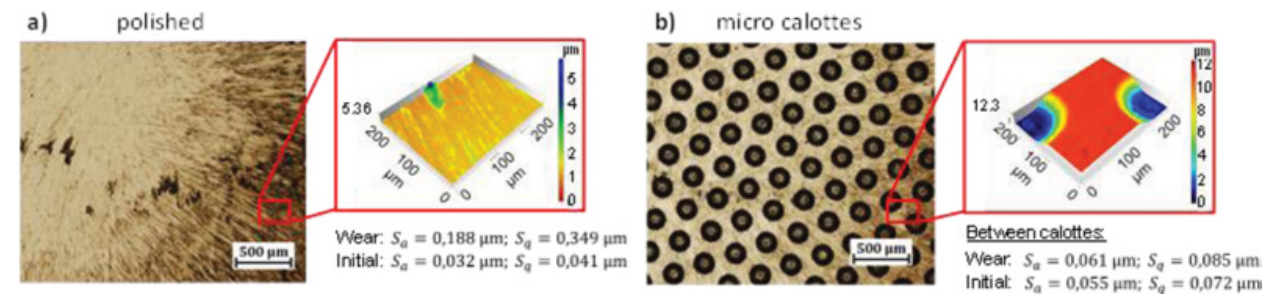

Figure 7. Wear at tool surfaces after last compression, polished (a) and micro calottes (b).

Figure 6 illustrates the resulting sample face side surface of dry compression with the polished reference tool (Fig. 6b) and lubricated compression with micro-calottes-tool (Fig. 6c) at a forming degree of -0,69 in comparison to the initial face side surface (Fig. 6a). Both compressed samples reached a friction factor of 0,2 but resulting in heavily different surface qualities, despite their similar tribological conditions. By comparing the shift of root square roughness $S_{\mathrm{q}}$ from initial to resulting surfaces at sample centre and sample boarder (Fig. 6c) it is evident, that the polished reference tools cause a strong flattening of the sample surface and a decreasing surface roughness, whereas the microstructured tool increases the resulting surface roughness by up to four times. The consequence of using the structured forming tool is a generated negative form of the micro calottes in the shape of small hills on the sample's surface.

Likewise the comparison of samples compressed by the polished stamps and stamps with micro calottes in Fig. 7 shows the difference between wear on the polished and microstructured surfaces. The polished surface in Fig. 7a shows clearly a high wear due to strong flattening impact onto the compression samples because of the very low surface roughness of the initial polished tool surface. In case of dry compression, this results in a higher real contact area without a separation of tool and workpiece surface by any lubrication and increases the appearance of adhesion wear. The 3D-scan in Fig. 7a shows workpiece material remaining on the polished tool surface, which leads to an drastically increase of surface roughness from initially $\mathrm{S}_{\mathrm{q}}=0,041 \mu \mathrm{m}$ up to resulting $0,349 \mu \mathrm{m}$. Compared to that, the tool stamps covered with micro calottes show no significant increase of surface roughness. The initial root square roughness between the calottes is only increasing from $S_{q}=0,072 \mu \mathrm{m}$ to resulting $0,085 \mu \mathrm{m}$.

\section{Summary}

By using the barrel compression test, the friction factor was determined for four different tool topographies, with two different workpiece materials, in dry and lubricated tribosystems, at forming degrees from $-0,17$ to $-1,3$. The tool topographies were results of possible finishing technologies polishing, grinding and spark erosion as well as a deterministic microstructuring by Jet-ECM. 
The friction factor increases rapidly with higher surface roughness for forming degrees under $\varphi=-0,8$ for both tested materials, whereas higher forming degrees are less dependent on the tool surface topography. By using a lubricated tribosystem, the friction was lowered in case of polished, grinded and with micro calottes structured tools. Tools with erosion craters show no significant impact under the influence of lubrication due to the absence of closed lubricant pockets within the interacting tool surface profile. Besides tribological conditions, workpiece and tool surfaces are affected drastically by the tool surface condition. Dry compressions with polished tools result in smooth workpiece surfaces but increase the appearance of adhesion wear. Whereas tools structured with micro calottes are showing just minimal wear in form of higher surface roughness but develop an unwanted negative form of micro calottes on the workpiece surface.

This research is supported by the Deutsche Forschungsgemeinschaft (DFG) in context of the Collaborative Research Centre/Transregio 39 PT-PIESA, subproject A02.

\section{References}

[1] U. Engel Wear 260: 265-273 (2006)

[2] F. Vollertsen, D. Biermann, H. Hansen, I. Jawahir, K. Kuzman, CIRP Annals - Manufacturing Technology 58(2): 566-587 (2009)

[3] E. Brinksmeier, O. Riemer, S. Twardy, Int. J. Mach. Tools Manuf. 50: 425-430 (2010)

[4] S. Weidel, S.U. Engel. Int. J. Adv. Manuf. Technol. 33: 130-136 (2007)

[5] M. Hackert-Oschätzchen, G. Meichsner, H. Zeidler, M. Zinecker, A. Schubert, Proc. ESAFORM 1353: 1337-1343 (2001)

[6] B. Eichenhüller, U. Engel, Proc. 3rd ICOMM'08, 207-210 (2008)

[7] P. Groche, J. Stahlmann, J. Hartel, M. Köhler, Tribol. Int. 42: 1173-1179 (2009)

[8] R. Ebrahimi, A. Najafizadeh, J. Mater. Process. Technol. 152: 136-143 (2004)

[9] K. Steinhoff, W. Rasp, O. Pawelski, Tribologie + Schmierungstechnik 2: 31-36 (1998) 